\title{
KATARAK PADA ANAK DI POLIKLINIK MATA BLU PROF. DR. R. D. KANDOU MANADO PERIODE JANUARI 2011 - DESEMBER 2013
}

\author{
${ }^{1}$ Geaby M. Irawan \\ ${ }^{2}$ J. S. M Saerang \\ ${ }^{2}$ Yamin Tongku
}

\author{
${ }^{1}$ Kandidat Skripsi Fakultas Kedokteran Universitas Sam Ratulangi Manado \\ ${ }^{2}$ Bagian Ilmu Kesehatan Mata Fakultas Kedokteran Universitas Sam Ratulangi Manado \\ Email: g.irawan_11_263@yahoo.co.id
}

\begin{abstract}
Cataract is the condition when tubidity happen to the fiber or the lens material inside the lens capsule. Lens turbidity may soon be known after the baby born or may happen between development time of the child. The prevalence of cataract in children in the world is around 15 per 10.000 cases. In developing country, child blindness due to cataract cases reach up to $1-4$ per 10.000 cases. This study aimed to get an idea of cataract disease in children in the eye clinic of the BLU RSU Prof. Dr. R. D. Kandou Manado in the period January 2011 - December 2013. This was a retrospective descriptive design using a medical recor. The samples in this study were children who came for treatment to the eye clinic of the BLU RSU Prof. Dr. R. D. Kandou Manado in the period of January 2011 - December 2013 who was diagnose with cataract disorders. The results showed that from the medical records in the period of January 2011 - December 2013, there were 29 patients with cataract children. There were more male cases than females (69\%). Of the 29 patients, most cataracts cases aged $10-14$ years (37.9\%). The most frequent type of cataract was the traumatic cataract (55.17\%).
\end{abstract}

\begin{abstract}
Abstrak: Katarak merupakan keadaan di mana terjadi kekeruhan pada serabut atau bahan lensa di dalam kapsul lensa. Kekeruhan lensa ini dapat diketahui segera setelah bayi lahir atau dapat terjadi selama masa perkembangan anak. Prevalensi katarak pada anak di dunia sekitar 15 per 10.00 kasus. Di Negara berkembang kasus kebutaan anak akibat katarak dapat mencapai 1-4 per 10.000 kasus. Penelitian ini bertujuan untuk mendapatkan gambaran kelainan katarak pada anak di Poliklinik Mata BLU RSU Prof. Dr. R.D. Kandou Manado periode Januari 2011 - Desember 2013. Metode Penelitian: Desain deskriptif retrospektif menggunakan catatan rekam medik. Sampel pada penelitian ini adalah anak-anak yang datang berobat ke Poliklinik Mata BLU RSU Prof. Dr.R.D. Kandou Manado pada periode Januari 2011 - Desember 2013 yang didiagnosis dengan kelainan katarak. Dari hasil catatan rekam medik pada periode Januari 2011 - Desember 2013, terdapat 29 penderita katarak anak. Penderita laki-laki lebih banyak daripada perempuan (69\%). Dari 29 kasus yang paling banyak menderita katarak anak kelompok umur 10 - 14 tahun (37,9\%). Jenis katarak anak yang terbanyak ialah katarak traumatic 16 penderita (55,17\%).
\end{abstract}

Kata kunci: katarak anak, jenis kelamin, umur, jenis katarak

Mata merupakan bagian yang sangat peka. Meskipun mata telah mendapat banyak perlindungan dari tulang orbita, bantalan lemak retrobulbar, kelopak mata dengan bulu matanya, dengan telah dibuatnya macam-macam alat untuk melindungi mata, tetapi frekuensi kecelakaan mata sangat tinggi. Katarak anak adalah kekeruhan lensa yang terjadi pada anak-anak. Kekeruhan lensa ini dapat diketahui segera setelah bayi lahir, atau dapat terjadi selama masa perkembangan anak. ${ }^{1,2}$ Berdasarkan 
data dari World Health Organization (WHO), katarak merupakan kelainan mata yang menyebabkan kebutaan dan gangguan penglihatan yang paling sering ditemukan. ${ }^{3}$ Prevalensi katarak pada anak di dunia sekitar 15 per 10.000 kasus. Di negara berkembang kasus kebutaan anak akibat katarak dapat mencapai 1-4 per 10.000 kasus. Oleh sebab itu, World Health Organization (WHO) mencanangkan program Vision 2020 untuk mengurangi berbagai penyebab kebutaan pada anak. ${ }^{4}$ Penelitian ini dilakukan untuk mendapatkan gambaran kelainan katarak pada anak di Poliklinik Mata BLU RSU Prof. Dr. R.D. Kandou Manado periode Januari 2011 - Desember 2013.

\section{METODE PENELITIAN}

Penelitian ini adalah suatu penelitian yang bersifat deskriptif retrospektif dengan meneliti data di Bagian Rekam Medik BLU RSU Prof. Dr. R.D. Kandou Manado. Penelitian ini dilakukan di Poliklinik Mata dan Bagian Rekam Medik BLU RSU Prof. Dr. R.D. Kandou Manado. Penelitian ini dilakukan pada bulan November 2014. Subjek penelitian ini adalah anak-anak yang datang berobat di Poliklinik Mata BLU RSU Prof. Dr. R.D. Kandou Manado pada periode Januari 2011 - Desember 2013 yang didiagnosis dengan kelainan katarak. Secara umum variabel penelitian ialah jenis kelamin, umur, dan jenis katarak anak. Bahan penelitian ialah Status pasien di Poliklinik Mata BLU RSU Prof. Dr. R.D. Kandou Manado.

\section{HASIL PENELITIAN}

Berdasarkan pengumpulan data yang dilakukan selama bulan November 2014 secara deskriptif retrospektif di Poliklinik Mata dan Bagian Rekam Medik BLU RSU Prof. Dr. R.D. Kandou Manado periode Januari 2011 - Desember 2013 maka didapatkan 29 penderita dengan katarak pada anak (Tabel 1).

Berdasarkan tabel di atas memperlihatkan bahwa dari 29 penderita katarak pada anak didapatkan paling banyak pada anak laki-laki yaitu sebanyak 20 penderita (69\%), sedangkan pada anak perempuan ditemukan sebanyak 9 penderita (31\%).

Tabel 1. Distribusi Katarak Pada Anak Di Bagian Ilmu Kesehatan Mata BLU RSU Prof. Dr. R.D. Kandou Manado Periode Januari 2011 - Desember 2013 Berdasarkan Jenis Kelamin

\begin{tabular}{ccc}
\hline $\begin{array}{c}\text { Jenis } \\
\text { Kelamin }\end{array}$ & Jumlah & $\begin{array}{c}\text { Presentase } \\
\mathbf{( \% )}\end{array}$ \\
\hline Laki - laki & 20 & $69 \%$ \\
Perempuan & 9 & $31 \%$ \\
TOTAL & 29 & $100 \%$ \\
\hline
\end{tabular}

Tabel 2. Distribusi Katarak Pada Anak Di Bagian Ilmu Kesehatan Mata BLU RSU Prof. Dr. R.D. Kandou Manado Periode Januari 2011 - Desember 2013 Berdasarkan Umur

\begin{tabular}{ccc}
\hline Umur (tahun) & Jumlah & $\begin{array}{c}\text { Presentase } \\
(\mathbf{\%})\end{array}$ \\
\hline$<1$ & 2 & $6,9 \%$ \\
$1-4$ & 6 & $20,7 \%$ \\
$5-9$ & 10 & $34,5 \%$ \\
$10-14$ & 11 & $37,9 \%$ \\
TOTAL & 29 & $100 \%$ \\
\hline
\end{tabular}

Berdasarkan tabel di atas memperlihatkan bahwa dari 29 penderita katarak pada anak didapatkan paling banyak pada anak - anak yang berumur 10 - 14 tahun, yaitu sebanyak 11 penderita ( $37,9 \%)$ sedangkan yang paling sedikit didapatkan pada umur $<1$ tahun yaitu sebanyak 2 penderita (6,9\%).

Tabel 3. Distribusi Katarak Pada Anak Di Bagian Ilmu Kesehatan Mata BLU RSU Prof. Dr. R.D. Kandou Manado Periode Januari 2011 Desember 2013 Berdasarkan Jenis Katarak

\begin{tabular}{ccc}
\hline $\begin{array}{c}\text { Jenis } \\
\text { Katarak }\end{array}$ & Jumlah & $\begin{array}{c}\text { Presentase } \\
(\%)\end{array}$ \\
\hline Katarak & 9 & $31,03 \%$ \\
Kongenital & 4 & $13,80 \%$ \\
Katarak & 16 & $55,17 \%$ \\
Juvenil & & \\
Katarak & & \\
Traumatik & & \\
TOTAL & 29 & $100 \%$ \\
\hline
\end{tabular}

Berdasarkan tabel di atas 
memperlihatkan bahwa dari 29 penderita katarak pada anak didapatkan paling banyak menderita jenis Katarak Traumatik sebanyak 16 penderita (55,17\%), sedangkan yang paling sedikit adalah jenis Katarak Juvenil dengan 4 penderita $(13,80 \%)$.

\section{BAHASAN}

Berdasarkan penelitian yang dilakukan selama periode November 2014 secara deskriptif retrospektif di Poliklinik Mata dan Bagian Rekam Medik BLU RSU Prof. Dr. R.D. Kandou Manado periode Januari 2011 - Desember 2013, maka didapatkan 29 penderita katarak pada anak yang datang berobat di Poliklinik Mata.

Dari data-data yang diperoleh berdasarkan hasil penelitian yang dilakukan menurut jenis kelamin penderita, didapatkan bahwa yang berjenis kelamin laki-laki merupakan kasus yang paling banyak terjadi yaitu sebanyak 20 penderita (69\%), sedangkan perempuan sebanyak 9 penderita (31\%). Hasil penelitian ini sama dengan hasil penelitian yang didapat sebelumnya oleh Johar et all dan PeruchoMartinez et al. Meskipun secara umum tidak ada predileksi jenis kelamin tertentu terhadap kejadian katarak pediatric, akan tetapi prevalensi tersebut disebabkan karena adanya ekspektasi sosial terhadap peran anak laki-laki dalam masyarakat dibandingkan dengan alas an biologis. ${ }^{5}$

Berdasarkan data yang terkumpul menurut pembagian umur anak yang menderita katarak, didapatkan bahwa anak umur 10 - 14 tahun yang lebih banyak yaitu sebanyak 11 penderita (37,9 \%), kemudian diikuti oleh golongan umur 5 - 9 tahun sebanyak 10 penderita (34,5\%), $1-4$ tahun sebanyak 6 penderita $(20,7 \%)$, dan yang terendah pada usia $<1$ tahun dengan jumlah penderita 2 orang (6,9\%). Hal ini menunjukkan bahwa kelainan katarak pada anak lebih sering terjadi pada masa pertumbuhan, dimana aktivitas anak semakin meningkat bersamaan dengan daya kerja mata yang juga terus bertambah. Selain itu yang menjadi salah satu penyebab adalah kemungkinan keterlam- batan diagnosis yang kemungkinan kurang mengertinya orangtua mengenai dampak jangka panjang yang diakibatkan oleh katarak terhadap penglihatan anak yang berakibat keterlambatan dalam mendapatkan tata laksana yang tepat dan dapat berakhir dengan kebutaan pada anak. ${ }^{6,7}$

Berdasarkan hasil dari jenis katarak, didapatkan bahwa jenis katarak traumatik sebagai kelainan yang paling sering terjadi yaitu sebanyak 16 penderita (55,17\%). Katarak traumatik paling sering disebabkan oleh cedera benda asing di lensa atau trauma tumpul terhadap bola mata. Lensa menjadi putih segera setelah masuknya benda asing karena lubang pada kapsul lensa menyebabkan humor aqueus dan kadang-kadang korpus vitreum masuk kedalam struktur lensa. Petasan, peluru pistol angin merupakan penyebab yang sering, penyebab lain yang lebih jarang adalah anak panah, batu, pajanan berlebih terhadap panas dan radiasi pengion. ${ }^{8}$

Berdasarkan hasil penelitian, didapatkan bahwa katarak kongenital yaitu sebanyak 9 penderita (31,03\%). Katarak kongenital adalah katarak yang mulai terjadi sebelum atau segera setelah lahir dan bayi berusia kurang dari 1 tahun. Katarak kongenital merupakan penyebab kebutaan pada bayi yang cukup berarti terutama akibat penangannya yang kurang tepat. $^{9}$

Berdasarkan hasil, jenis katarak juvenile sebanyak 4 penderita $(13,80 \%)$. Katarak juvenile merupakan kelanjutan dari katarak kongenital. Katarak juvenile biasanya merupakan penyulit penyakit sistemik ataupun penyakit metabolik lainnya seperti katarak metabolik, katarak traumatik, katarak komplikata, dan kelainan kongenital lain. ${ }^{10}$

\section{SIMPULAN}

Berdasarkan hasil penelitian secara desktiptif retrospektif di Poliklinik Mata dan Bagian Rekam Medik BLU RSU Prof. Dr. R.D. Kandou Manado periode Januari 2011 - Desember 2013, maka dapat disimpulkan bahwa :

1. Terdapat 29 penderita kelainan katarak 
pada anak .

2. Penderita laki-laki lebih banyak ditemukan yaitu sebanyak 20 penderita (69\%) dibandingkan dengan perempuan sebanyak 9 penderita (31\%).

3. Kelompok umur $10-14$ tahun merupakan kelompok umur yang paling sering ditemukan kelainan katarak pada anak, yaitu sebanyak 11 penderita (37,9\%).

4. Dari 29 penderita kelainan katarak pada anak, jenis kelainan katarak yang paling sering ditemukan adalah jenis katarak traumatik sebanyak 16 penderita ( 55,17\%), kemudian diikuti katarak kongenital sebanyak 9 penderita (31,03\%), katarak juvenile sebanyak 4 penderita $(13,80 \%)$.

\section{SARAN}

1. Bagi Bagian Ilmu Kesehatan Mata Poliklinik Mata BLU Prof. Dr. R.D. Kandou Manado, penyuluhan tentang kesehatan mata terhadap masyarakat sebaiknya rutin dilakukan agar masyarakat semakin mengerti dan tahu bahwa betapa pentingnya menjaga kesehatan mata dan membuat program penanggulangan untuk penyakit katarak khususnya pada anak.

2. Bagi masyarakat khususnya para orangtua agar dapat memperhatikan perilaku aktivitas melihat pada anak agar apabila terjadi kelainan dapat segera ditangani.

3. Pada kasus mata sebaiknya diberikan kode umur anak agar lebih mudah, supaya penelitian lebih lanjut bias lebih cepat.

4. Diharapkan adanya penelitian lebih lanjut mengenai katarak pada anak dengan variabel yang lebih diperluas.

\section{DAFTAR PUSTAKA}

1. Perucho-Martínez S, De-la-Cruz-Bertolo J, and Tejada- Palacios P. Pediatric Cataracts: Epidemiology and Diagnosis, Retrospective Review of 79 Cases. Archivos de la Sociedad
Espanola de Oftalmologia. 2007; 82(1): 37-42

2. Iqbal M, Jan S, Khan MN, Iqbal A, and Mohammod S. Pediatrics Intraocular Lens Implantation Complications and Visual Outcome. Pakistan Journal of Medical Research. 2004;43 (3): 108112

3. Departemen Kesehatan Republik Indonesia.2003. Rencana Strategi Nasional Penanggulangan Gangguan Penglihatan dan Kebutaan (PGPK) Untuk Mencapai Vision 2020. Jakarta, Indonesia, p.1

4. Resnikoff S, Pascolini D, Moriotti P. S, Pokharel P. P (2008): Global Magnitude of Visual Impartment cause of Uncorrected Refractive Error in 2004. Bulletin of World Health Organization. Volume 86. Number 1.

5. Adhikari S, Badhu BP, Bhatta NK, Jha $\mathbf{C B}$, Baral $\mathbf{N}$ and Kumari $\mathbf{N}$. Etiology and Clinical Profile of Pediatric Cataract in a Tertiary Care Centre of Eastern Nepal. Journal of the Nepal Medical Association. 2007; 46 (167): 94-98.

6. Reddy AK, Ray R, and Yen KG. Surgical Intervention for Traumatic Cataracts in Children: Epidemiology, Complications, and Outcomes. Journal of the American Association for Pediatric Ophthalmology and Strabismus. 2009:13(2): 170-174.

7. Mwende J, Bronsard A, Mosha M, Bowman $\mathbf{R}$, Geneau $\mathbf{R}$ and Courtright P. Delay in Presentation to Hospital for Surgery for Congenital and Developmental Cataract in Tanzania. The British Journal of Ophthalmology. 2005;8 (11): 14781482.

8. Vaughan \& Asbury. OFTALMOLOGI UMUM (Vaughan \& Asbury's General Ophthalmology). Edisi 17. Jakarta, Penerbit Buku Kedokteran EGC,2009, p. 170

9. Ilyas, S. Penuntun Ilmu Penyakit Mata, Ed.3. Jakarta, Balai Penerbit FKUI,p. 128-129, 132

10. Anonimus. Katarak Juvenil [online] 2010 [Accessed feb.16,2010]; Available from URL: http://Buzusima.co.cc. 